Journal of the

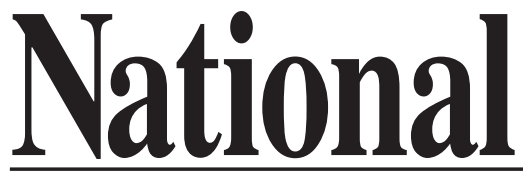

Academy or

Forensic
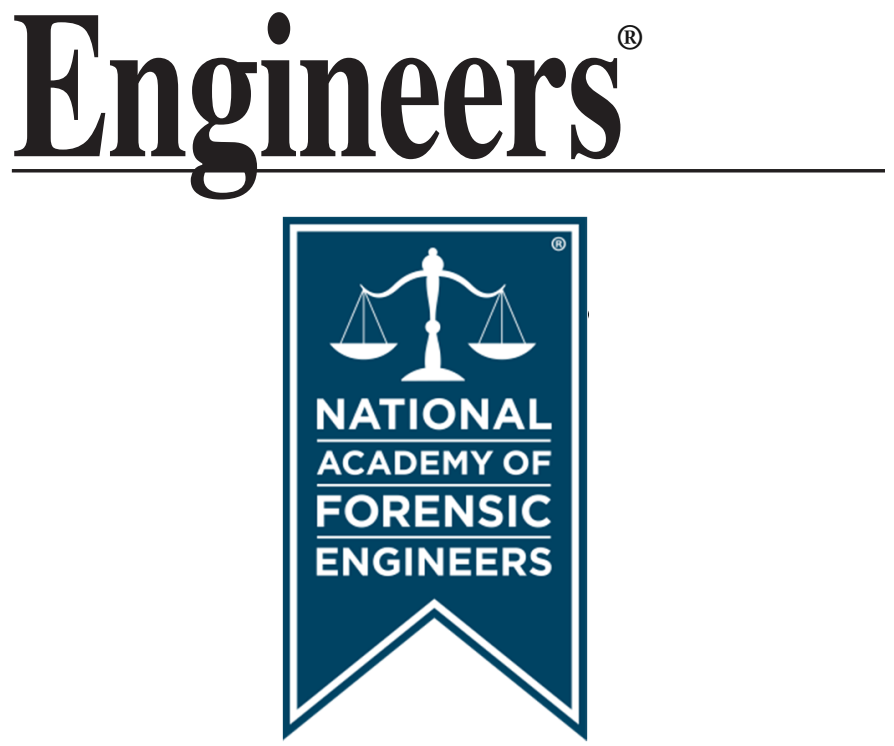

http://www.nafe.org ISSN: 2379-3252 


\section{Forensic Engineering Analysis of Propeller Contact Injury}

by Laura L. Liptai, Ph.D. (NAFE C339)

Paul Kamen, N.A. (NAFE C396)

Human contact with a small craft's propeller can cause serious injury. Propellers are large, heavy, sharp, very strong, almost knife-like, and spin at high rotational velocities. On a small high-speed recreational craft, the propeller blade tip velocity may be four to five times the vessel speed.

Propeller injuries are generally quite severe, often involving multiple deep lacerations with and without cortical (bone) damage distributed over a wide area of the body. There is a characteristic pattern to the geometry of these injuries. With a co-ordinate system defined relative to the boat "at rest," each cut corresponding to the path of a propeller blade as the moving water pulls the body through part of the area swept by the propeller. This unique pattern is the physical evidence of the overboard person's trajectory and can yield information about the point of water entry relative to the vessel.

Applications requiring high thrust at a relatively low speed, such as water skiing, wakeboarding and parasailing, result in unusual demands on both the propulsion system and on the maneuvering capabilities of the vessel (see Figure 1). As a result, there are additional hazards associated with propeller contact that may not be anticipated by even experienced small craft operators.

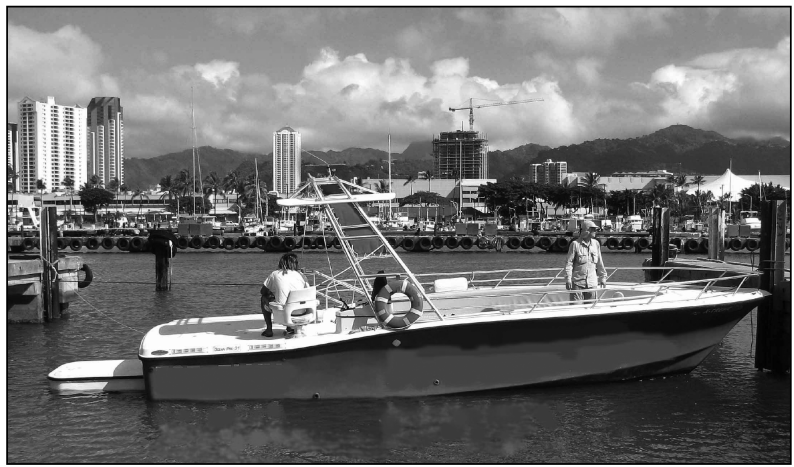

Figure 1

Lateral view of a parasail winchboat

Laura Lynn Liptai, Ph.D., 1660 School St. \#103, Moraga, CA 94556 and Orlando, FL Paul Kamen, 1224 Campus Drive, Berkeley, CA 94708 
Copyright (? National Academy of Forensic Engineers (NAFE) http://www.nafe.org. Redistribution or resale is illegal. Originally published in the Journal of the NAFE volume indicated on the cover page. ISSN: 2379-3252

\section{Keywords}

Forensic Engineering, Biomechanics, Propeller Injury, Boat Injury, Personal Water Craft, Parasailing, Surface Piercing Propeller

\section{Scope}

The scope of this forensic analysis applies only to the principal causal factors of the subject parasailing incident and should not be extrapolated to other incidents. Since the product issues were outside the scope of this assignment, the results of this forensic analysis do not apply to product design. The BioMedical Engineering analysis discussed at length below, includes kinematics, trauma analysis, laceration timing and operator perception-response. Retention of the authors was by the parasailing operator.

\section{BioMedical Engineering Analysis}

Immediately prior to the accident, two first-time parasailers were on the flight deck preparing to hook up to the parachute towline as shown in Figure 2, with the assistance of a crewmember on the flight deck. The wind was reported to be approximately 15 knots from ahead, the boat speed was 1.5 knots or less, and the engine speed was approximately 1000 RPM.

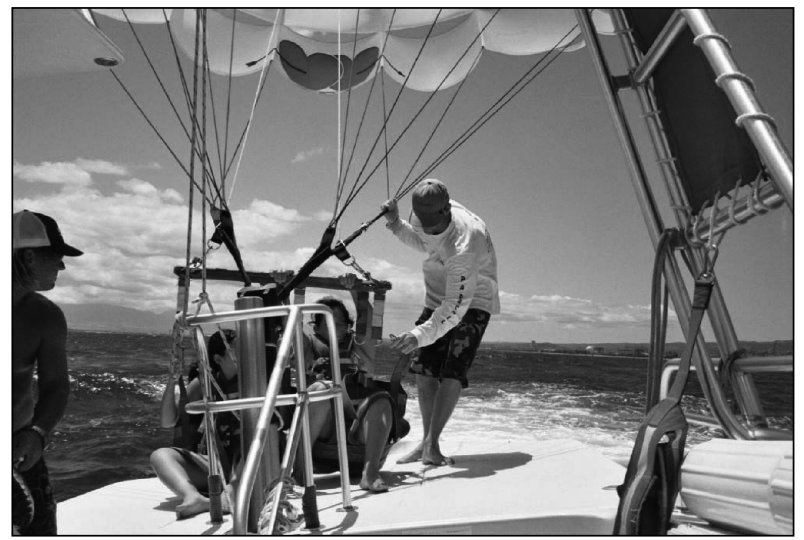

Figure 2

Launching parasailers from the "flight deck" at the aft end of the winchboat

A gust of wind (reported as 40 knots by the vessel operator and estimated at 35 knots from the calculations) was accompanied by a counter-clockwise wind shift. The gust and wind shift caused the towlines to swing suddenly to starboard (right side of the boat when looking forward). Although the two parasailers were not hooked into the harness, the lead lines surrounded them on three sides. All three people on the flight deck went overboard, landing in the water on the starboard side. The impetuses for the fall are a spreader bar (structure connecting the 
Copyright @ National Academy of Forensic Engineers (NAFE) http://www.nafe.org. Redistribution or resale is illegal. Originally published in the Journal of the NAFE volume indicated on the cover page. ISSN: 2379-3252

tow lines) and parachute movement. Following the wind gust, the chute dove roughly ninety degrees to starboard and one of the three persons that fell overboard on the starboard side landed anterior to (forward of) the corner of the stern (rear). This occupant, a 25 year old female, landed most proximal to the propeller and sustained multiple deep lacerations and fractures. The other two persons overboard were not as close to the stern and thus not injured.

The trauma diagnosed and documented by the health care providers in the incident is outlined in Figure 3. Forensic kinematic analysis of the physical evidence including medical records, injury photographs, topographical vessel and overboard kinematic (movement) data follows:

- Right and left ankle lacerations are at similar angles consistent with lower extremity positional and time proximal events bilaterally.

- Right distal leg laceration is more perpendicularly oriented to the long axis of the tibia at the time of contact, as consistent with laceration evidence.

- Right mid leg laceration is also more perpendicular, relative to the more parallel oriented ankle lacerations.

- Right proximal leg laceration occurs more parallel to the long axis, which is consistent with horizontal alignment of the lower extremity and more parallel orientation to the propeller blades.

Face: a traumatic symmetrical.

No neck or back trauma noted

Open R tib pilon fracture (fx).

Open R tibial shaft and medial.

Malleolar fractures.

Open $\mathrm{R}$ talus fracture.

Laceration to R extensor hallucis longus, anterior tib, anterior artery, deep peroneal nerve, and all of the extensor digitorum communis to the toes.

Open $L$ talus $\mathrm{fx}$.

Open $L$ tibial plateau $\mathrm{fx}$ and mildly distracted medial malleolar fx. Fx line does extend into tibiotalar joint.

Each laceration 5-6 cm (1.7"-2.36").

4 lacerations to R LE (lower extremity) and

2 large lacerations to $L$ LE. Also partial amputation of the $\mathrm{R}$ foot on the dorsal aspect.

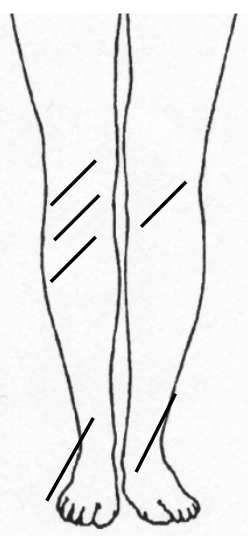


Copyright @ National Academy of Forensic Engineers (NAFE) http://www.nafe.org. Redistribution or resale is illegal Originally published in the Journal of the NAFE volume indicated on the cover page. ISSN: 2379-3252

Based on kinematic tests, the plaintiff most likely fell into the water laterally with torso flexion or posteriorly (supine/face up) with torso flexion and sustained laceration trauma within seconds. The kinematic study determined juxtapositions of the body proximal to the propeller and mechanics of the lacerations. An outline of the analysis and findings follows.

There is no physical evidence of forceful head impact on the deck or adjacent to the boat. The injured plaintiff was retrieved from the port stern (left rear) aspect of the boat with her glasses still on her face. Eye glass retention testing, conducted from flight deck to the water, determined that the anterior prone (with and without flexion) fall kinematics could be ruled out if her glasses remained on her face.

The proximal location of lower extremities, the short duration of time required for the boat to translate, the depth required to come into contact with the propeller in the far aft location (beneath the horseshoe rudder) and the juxtaposition of the trauma are consistent with the injury occurring within seconds following the initial fall into the water. The rotational inertia of the propeller and entrained water was used in estimating the energy available to cause the lacerating trauma (detailed in Attachment A).

Testing was performed to determine the point of blade contact as a function of the lateral velocity of the boat and initial distance away from the deck in the water.

Perception-Response analysis determined that based on the 6.2 second propeller spin down, reaction time could not likely be improved to prevent the trauma. According to the crew member that went overboard, it was a split second before he called out and an additional one to two seconds before the engine was cut. Regardless of witness recollection, propeller power-down testing (detailed in Attachment A) on the subject propeller revealed a minimum of 6.2 seconds for the propeller to spin down to 3 revolutions per second. Utilizing visual perception-reaction time per Collins (ref. 5) plus propeller spin down time of $6.2 \mathrm{sec}-$ onds, total time for perception, reaction and propeller spin down equals a minimum of 7.7 seconds. Therefore, the long run-down time of the propeller after being put in neutral while the boat is subject to wind-induced motion makes it unlikely that operator reaction time could be improved to prevent the trauma. Operator and vessel handling options will be detailed in the next section.

\section{Unanticipated hazards}

In the context of propeller contact trauma, several unanticipated vessel hazards are analyzed in this paper. The first is the size and shape of the inflow field upstream of a propeller operating at relatively high thrust and low forward speed. This is the case for water-ski or wake board towboats, especially during 
the initial acceleration phase of their operation, and for parasail winchboats, especially when operating against a headwind. The second is the unusual maneuvering characteristics of the vessel while being pulled backwards or sideways by parachute wind loads. The third is the unusually far aft and close-to-thesurface location of the propeller compared to conventional drive configurations. Lastly, the fourth is the relatively long run-down time of the propeller after being put in neutral while the boat is subject to wind-induced motion.

\section{Propeller inflow}

Propellers work by accelerating water in the aft direction, resulting in forward thrust on the propeller blades by momentum conservation. To better understand how propellers work, consider a propeller as an idealized "actuator disk" with no discrete blades.

The volume of water flowing into the actuator disk from ahead must equal the volume flowing out behind, so conservation of mass, along with the incompressibility of water, demand that the speed of the water flow entering the disk equal the speed of departure. Recreational boat operators often believe that water enters the propeller at the forward speed of the vessel but exits at the high speed of the slipstream. This is not the case for the idealized thin actuator disk model, and not true for most real propeller propulsion systems.

The idealized propeller model can only change the pressure, not the velocity, of the water as it flows through the disk. The propeller thrust is the pressure difference acting on the disk. Momentum is transferred and energy is absorbed as the water accelerates towards the propeller disk from ahead, and continues to accelerate as it leaves the propeller in the slipstream.

This leads to the characteristic "wine bottle" flow pattern into and out of a propeller (Figure 4). Continuity and Bernoulli both require that the flow field some distance upstream is wider than the propeller disk, and that the flow field necks down as it accelerates and the pressure drops. As the water passes through the actuator disk, the pressure is increased from below ambient to above ambient. The flow continues to accelerate and contract until it reaches ambient pressure again in a narrow slipstream jet.

Note that energy is lost in the slipstream jet. The energy lost equals mass flow times velocity squared, divided by two, but momentum change (and therefore thrust) equals mass flow times velocity change only to the first power. Therefore, it is more efficient if a larger actuator acts on a larger volume of water with relatively little velocity change. This maximizes the thrust with a minimum of lost energy. 
Copyright $\odot$ National Academy of Forensic Engineers (NAFE) http://www.nafe.org. Redistribution or resale is illegal. Originally published in the Journal of the NAFE volume indicated on the cover page. ISSN: 2379-3252

A consequence of this actuator disk model is that larger propellers turning at slower rotational speeds are more efficient than smaller propellers at a higher revolutions per minute ("RPM"). This in fact is the case for most vessels except those operating at relatively high speeds, where frictional resistance limits the efficiency of large propellers. Most propulsion systems would be more efficient with larger propellers and deeper reduction ratios (the engine RPM divided by the propeller RPM), but the disproportionate cost of larger propellers and hightorque drivelines, along with limiting geometric considerations (e.g. blade tip clearance and shaft angle) requires smaller propellers and shallower reduction ratios than is hydrodynamically optimal. A comparison of propeller geometry for different drive types is outlined in Table 1.

The actuator disk theory further explains why waterjets are not efficient for high thrust applications such as water skiing and parasailing. The small area of the waterjet nozzle requires much higher outflow velocity to achieve the same thrust as a propeller, with considerably more energy lost in the slipstream. Although waterjets are safer with respect to propeller contact injuries - as there is no external propeller - waterjets may be inappropriate for these applications.

The shape of a propeller inflow field is a function of a parameter called "Thrust Load Coefficient" or $\mathrm{C}_{\mathrm{t}}$. This is the ratio of the propeller thrust pressure (thrust force divided by propeller disk area) to the dynamic pressure, or "velocity head" corresponding to the vessel's speed.

$$
\begin{aligned}
& \mathrm{C}_{\mathrm{t}}=(\mathrm{T} / \mathrm{A}) /\left(\text { rho } * \mathrm{~V}^{\wedge} 2 / 2\right) \\
& \text { where: } \quad C_{t}=\text { thrust load coefficient } \\
& \mathrm{T}=\text { propeller thrust } \\
& \mathrm{A}=\text { area of propeller disk } \\
& \text { (area of circle swept by blades) } \\
& \text { rho }=\text { mass density of the fluid } \\
& \mathrm{V}=\text { velocity of boat, in consistent units. }
\end{aligned}
$$

At zero forward speed with finite thrust, $\mathrm{C}_{\mathrm{t}}$ goes to infinity because dynamic pressure is zero when speed is zero. However, at high speed, all the available engine power is absorbed with a relatively small increase in flow velocity, resulting in a small $\mathrm{C}_{\mathrm{t}}$.

Captain Saunders, in his classic work Hydrodynamics in Ship Design, (ref.1) presents a diagram illustrating the dependence of inflow field shape on $\mathrm{C}_{\mathrm{t}}$. 
Copyright @ National Academy of Forensic Engineers (NAFE) http://www.nafe.org. Redistribution or resale is illegal. Originally published in the Journal of the NAFE volume indicated on the cover page. ISSN: 2379-3252

NAFE C339/C396

PROPELLER CONTACT INJURY

PAGE 7

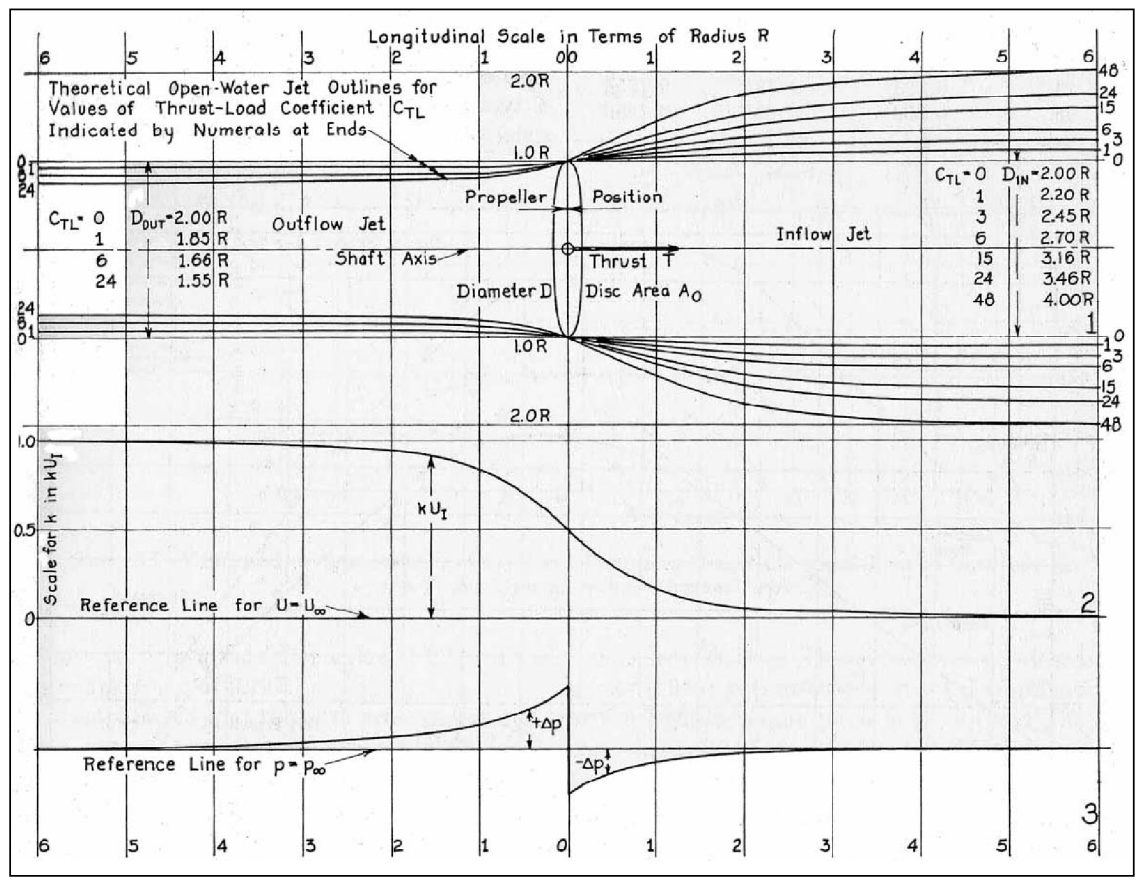

Figure 4

Propeller inflow and outflow as a function of $\mathrm{C}_{\mathrm{t}}$ : Theoretical Jet Outlines, AxialVelocity Distribution, and Axial-Pressure Distribution for an Ideal Screw Propeller

In the case of ski towboats and parasail winchboats, relatively low speeds and high thrust values are common. The resulting high $\mathrm{C}_{\mathrm{t}}$ values result in a field of wider inflow than would be experienced at high speed or at low thrust.

While the operator may only be aware of the outflow jet, the inflow field ahead of the propeller is by far more dangerous, especially when it is wider than the propeller diameter. If forceful, the propeller inflow fields could possibly pull in limbs and torsos along with the upstream water. Think of these fields as horizontal and very powerful swimming pool drains. The widening of the inflow field as speed drops and thrust load coefficient increases will likely not be familiar to the majority of vessel operators, and it is far less likely to be understood by swimmers in close proximity to a propeller operating at high $\mathrm{C}_{\mathrm{t}}$.

\section{Maneuverability under aft tow load}

There is an increased likelihood of placing overboard occupants near the propellers of the tow vessels referenced above. In the case of ski and wakeboard towboats, the skier or wakeboarder normally enters the water near the stationary propeller to begin the ski set. In the case of parasail winchboats, the parasailing 
Copyright $\odot$ National Academy of Forensic Engineers (NAFE) http://www.nafe.org. Redistribution or resale is illegal. Originally published in the Journal of the NAFE volume indicated on the cover page. ISSN: 2379-3252

passenger should not enter the water. However, deployment and retrieval of parasail riders requires an unobstructed aft (rear) deck with no rails around the stern (back) of the vessel (Figure 2), making accidental water entry near the stern of the boat a more likely occurrence than on other types of boats.

In the subject case, prior to hooking into the harness, one crew member and two passengers fell overboard while surrounded by lead lines due to a sudden gust and wind shift. The parachute was already deployed and fully inflated, flying close to the boat and exerting considerable backwards and side thrust on the vessel.

The boat in this case was equipped with a surface-piercing propeller and drive system as well as a horse-shoe rudder (Figure 5). The surface-piercing propellers are desirable from a performance point of view for a variety of reasons, but in this instance, the surface drive type may have contributed to a handling challenge resulting in the parasailers going overboard.

Similar boats with conventional drives are reported to pull straight back when aft-pulling parachute forces exceed forward-

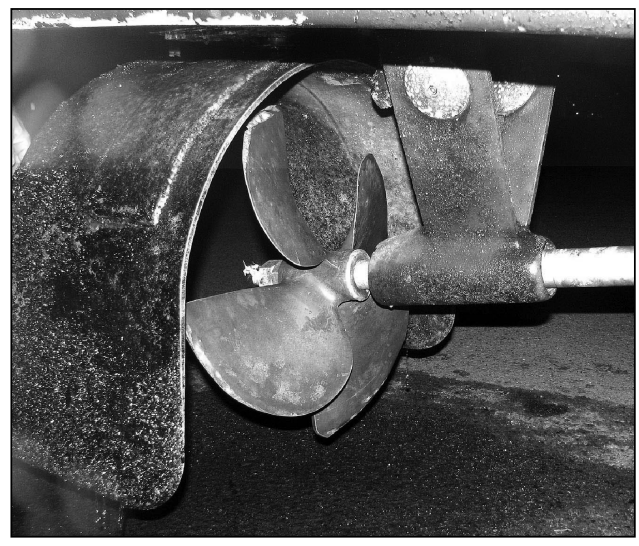

Figure 5

Propeller and horse-shoe rudder of surface-piercing drive system pushing propeller thrust. However, the surface drive configuration places a number of additional drag elements, particularly a large rudder, much further aft than conventional propulsion systems, as shown in Figure 6.

As a result of additional drag elements, this vessel did not align itself to a new wind direction when it was blown backwards or sideways in a sudden gust. Instead it rotated to approximately $90^{\circ}$ to the wind direction similar to a "hove to" orientation.

\section{Position of the propeller}

Surface-piercing propellers are necessarily far aft and close to the surface compared to conventional propellers. This propeller placement, combined with the propensity of the boat to drift sideways rather than along its longitudinal axis, presented vessel handling challenges. The 25 -year-old was pulled overboard and passed under the stern and across the bottom of the propeller, sustaining bilateral lower extremity trauma. 
Copyright $\odot$ National Academy of Forensic Engineers (NAFE) http://www.nafe.org. Redistribution or resale is illegal. Originally published in the Journal of the NAFE volume indicated on the cover page. ISSN: 2379-3252
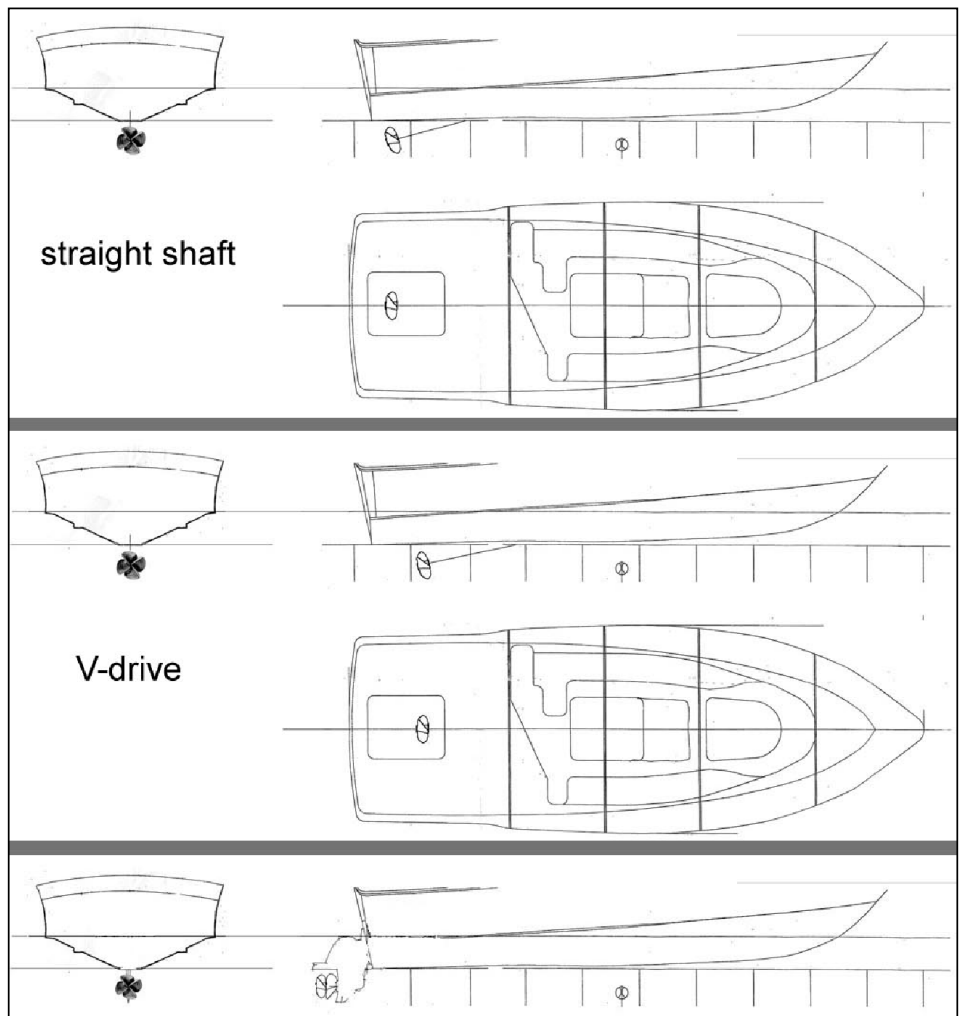

stern drive
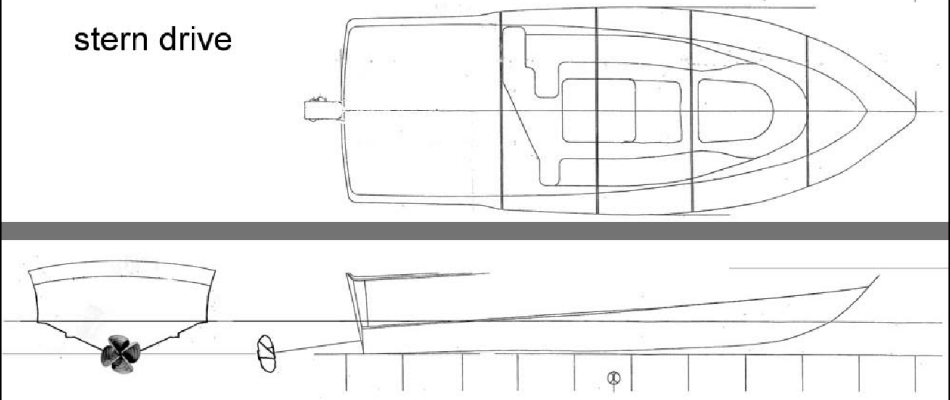

surface drive

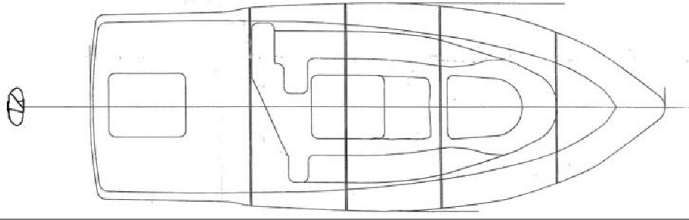

Figure 6

Composite 4-frame comparison of various drive configurations 


\section{Typical Geometry for Various Propulsion Configurations}

\begin{tabular}{|c|c|c|c|}
\hline $\begin{array}{l}\text { Top of } \\
\text { propeller } \\
\text { below water } \\
\text { surface (in) }\end{array}$ & $\begin{array}{l}\text { Distance of } \\
\text { Propeller hub } \\
\text { below transom } \\
\text { bottom (inches) }\end{array}$ & $\begin{array}{l}\text { Distance of } \\
\text { propeller aft } \\
\text { or forward } \\
\text { of transom (ft) }\end{array}$ & $\begin{array}{l}\text { Propeller } \\
\text { diameter } \\
\text { (inches) }\end{array}$ \\
\hline
\end{tabular}

\begin{tabular}{|c|c|c|c|c|}
\hline Surface drive A & 8.9 & 0 & $3.5 \mathrm{aft}$ & 24.25 \\
\hline Surface drive B & 8.9 & 0 & $2.8 \mathrm{aft}$ & 24.25 \\
\hline $\begin{array}{l}\text { Inboard } \\
\text { (straight shaft) }\end{array}$ & 28 & 15 & $1.5 \mathrm{fwd}$ & $16-18$ \\
\hline Inboard (V-drive) & 31 & 18 & 3.0 fwd & $16-18$ \\
\hline $\begin{array}{l}\text { Volvo DP-H } \\
\text { Sterndrive }\end{array}$ & 24.2 & 10.9 & $1.7 \mathrm{aft}$ & 15.4 \\
\hline
\end{tabular}

Table 1

Comparison of propeller geometry for different drive types

\section{Time required to stop propeller rotation}

Although this effect appears to be generally understood by experienced boat operators, it can be a major contributor to propeller contact accidents, especially in the case of parasail winchboats where a large towing force continues to be applied to the boat via wind and the inflated parachute even after power is cut and boat speed is low. On a windy day, the effect is to keep the boat moving through the water, which produces considerable torque on the propeller. The result is that the propeller continues to turn for many seconds after propeller power is cut.

Once the vessel operator recognized the emergency of people in the water, there were three hypothetical choices: a) use power and steering to maneuver the stern of the vessel, and therefore maneuver the propeller, away from overboard parasailers and crew; b) shift the gearbox into neutral to disconnect the propeller from the engine; or c) cut engine power but leave the propeller in gear so that propeller rotation stops quickly. Generally, circumstances and power train characteristics dictate which course of action is best.

\section{Forensic Engineering Analysis and Findings}

Beyond the BioMedical Engineering tests (topographic kinematics/mechanics, buoyancy sufficiency, eye glass retention and propeller RPM decrement [detailed in Attachment A]), six additional test results are summarized here and detailed in Attachment A: thrust and steering force, static roll stability, parachute towline force, steering sensitivity, hydrodynamic forces on the hull and rotational inertia of the propeller. 
Copyright @ National Academy of Forensic Engineers (NAFE) http://www.nafe.org. Redistribution or resale is illegal. Originally published in the Journal of the NAFE volume indicated on the cover page. ISSN: 2379-3252

The side force from the towline was found to be considerably greater than the available transverse steering thrust, demonstrating that it would likely not have been possible to move the stern of the boat transversely to avoid propeller contact.

The large number of helm turns required to control the rudder on this vessel may require additional time for the captain to quickly maneuver the boat in an emergent attempt to move the propeller away from a person in the water.

The time required for the propeller to stop turning after the gearbox is shifted into neutral is too long to have prevented injury in this accident even if the gearbox had been immediately shifted into neutral.

The response of the vessel to the wind gust and subsequent changes in the towline loads are calculated using a basic time-domain force and motion analysis, implemented on an excel spreadsheet for time steps of 0.1 second (Figure 7). For each time step, calculated aerodynamic and hydrodynamic forces are applied to the mass of the vessel and entrained water to compute the new velocity and position for the next time step.

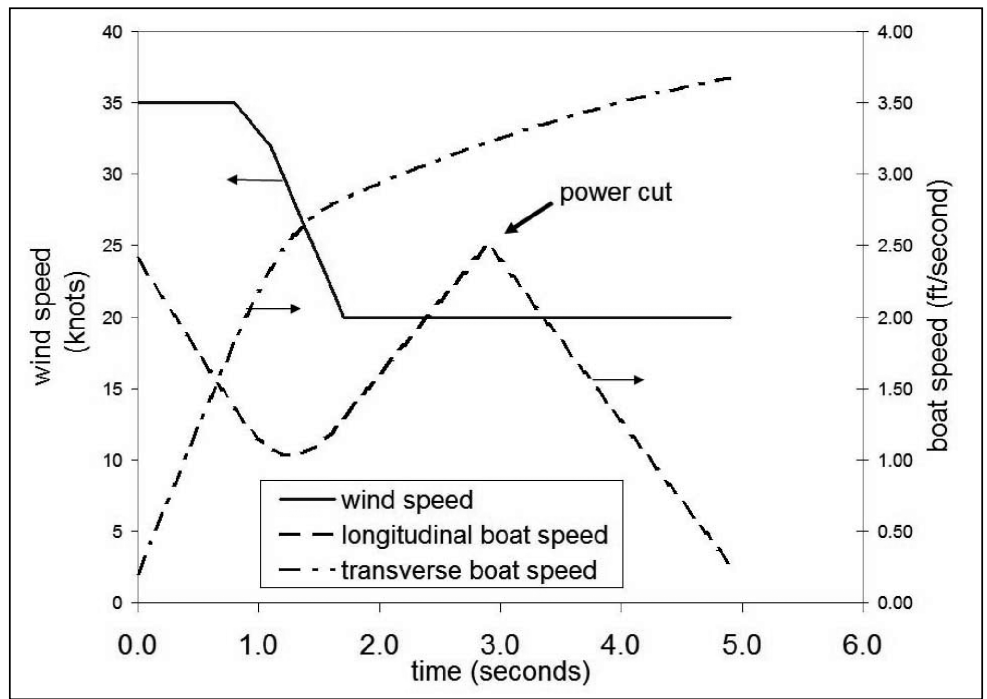

Figure 7

Vessel response to wind gust and power change

During the four seconds following the initiation of the gust, the analysis shows that the average transverse speed of the vessel was approximately 1.5 knots and increasing, and the average forward speed was approximately 1.0 knots. Forward speed first decreases in response to the high towline force when 
Copyright @ National Academy of Forensic Engineers (NAFE) http://www.nafe.org. Redistribution or resale is illegal. Originally published in the Journal of the NAFE volume indicated on the cover page. ISSN: 2379-3252

the gust hits, then increases as the gust subsides, but begins to drop again after the gearbox is shifted to neutral, three seconds after the initial gust onset.

The maximum heel angle during the gust event was approximately sixteen degrees.

After initiation of the gust, torque on the propeller due to vessel motion tends to keep the propeller spinning for at least six seconds after the gearbox is shifted into neutral.

Inertial energy in the rotating propeller decreases from $992 \mathrm{ft}-\mathrm{lb}$ to $82 \mathrm{ft}-\mathrm{lb}$ over a six second interval after the gearbox is shifted to neutral.

The transverse motion of the vessel, combined with the shallow and extremely far aft location of the propeller, principally caused one of the passengers to pass underneath the stern of the vessel where bilateral lower extremities were severely injured by propeller contact.

The trajectory of the victim underneath the aft deck of the vessel, and the orientation of the injuries with respect to the plaintiff's anthropometrics (anatomical geometry) and the location of the propeller blades, are found to be consistent with the calculated motions of the vessel in response to the wind gust.

\section{Findings}

These analytical results indicate that a key factor in the cause of the injury was the configuration of the vessel with a surface-piercing propeller for a parasailing application. A conventional drive system would have allowed the vessel the normal tendency to align with the wind direction upon being pulled backwards by a strong wind gust. Even at low forward speeds, the same gust on a conventionally powered boat would likely not result in the strong relative crosswind which contributed to the parasailers and a crew member going overboard. Once in the water, the transverse motion of the boat was a principal causal factor in the proximity to, and contact with, the propeller.

The extreme aft and shallow location of the propeller were causal factors that placed the overboard passengers at risk.

The configuration of the steering system, with a large number of turns required to make significant adjustments to the rudder angle, made it unlikely that the operator could maneuver the stern of the boat away from people in the water in time to prevent the propeller contact. 
Copyright $\odot$ National Academy of Forensic Engineers (NAFE) http://www.nafe.org. Redistribution or resale is illegal.

Originally published in the Journal of the NAFE volume indicated on the cover page. ISSN: 2379-3252

\section{References}

1. Saunders, Harold E. Hydrodynamics in Ship Design, Vol. II. Society of Naval Architects and Marine Engineers, New York, 1957.

2. Hoerner, S.F., Fluid-Dynamic Drag: Theoretical, Experimental and Statistical Information, Sighard F. Hoerner, Midland Park, NJ, 1958.

3. Sarpkaya, T., and Isaacson, M., Mechanics of Wave Forces on Offshore Structures, Van Nostrand, New York, 1981, ISBN = 0-442-25402-4.

4. Propeller Selection for Boats and Small Ships, E Marine Training - Prop Matching, and associated spreadsheet "Approximate WR^2 of Typical Propeller," U.S. Coast Guard Small Craft Engineering Center, February 2005.

5. Collins, James, Accident Reconstruction, Charles C. Thomas, 1979.

\section{Acknowledgements}

Mr. Kamen and Dr. Liptai would like to acknowledge their colleagues and the important contributions of: John Manning, Ph.D., San Francisco, CA, and Clyde Calhoun, Waianae, HI. We would also like to thank attorneys Roy Yempuku, Matt Monroe and Jill Hillman for granting us the opportunity to develop this unique testing protocol analysis. Furthermore, Dr. Laura Liptai gratefully acknowledges the tutelage of her late father, Robert G. Liptai, Ph.D. 
Copyright @ National Academy of Forensic Engineers (NAFE) http://www.nafe.org. Redistribution or resale is illegal. Originally published in the Journal of the NAFE volume indicated on the cover page. ISSN: 2379-3252

\section{Attachment A: Tests and Calculations}

The authors conducted a series of full-scale tests finding that: a) the power setting used to maintain position yielded insufficient steering force to maneuver the propeller clear of people in the water; b) under the wind conditions present at the time of the accident (moderate trade winds, with significant gusts) there was a considerable time lag between shifting to neutral and stopping the propeller; and c) the physical evidence of the injuries reconstructed the movement of the vessel through the water relative to the plaintiff overboard.

\section{Thrust and steering force}

In order to determine thrust and steering forces relative to a vessel's response to parachute wind load, static thrust and steering yaw torque were measured directly using the subject vessel.

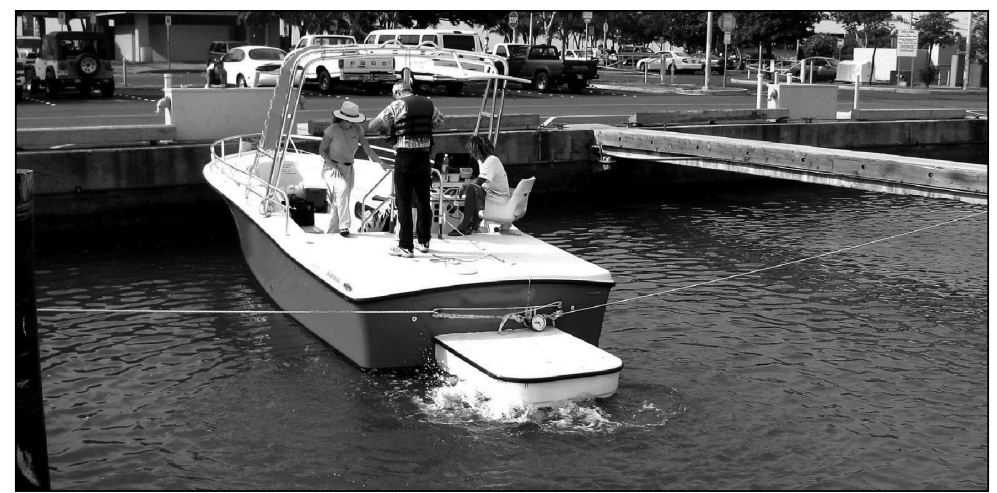

Figure A-1

Winchboat in test basin for steering thrust measurement

Static thrust at various engine and propeller speeds was measured directly using a calibrated spring dynamometer.

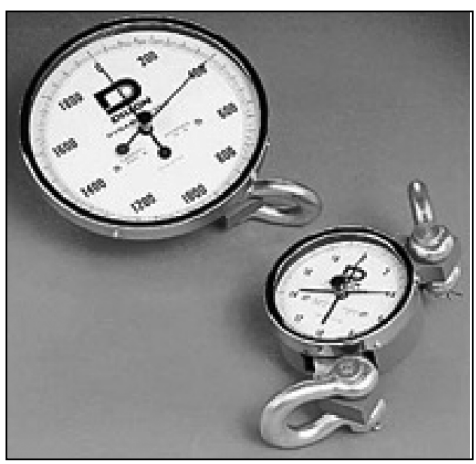

Figure A-2

Dynamometer 
Copyright @ National Academy of Forensic Engineers (NAFE) http://www.nafe.org. Redistribution or resale is illegal.

Originally published in the Journal of the NAFE volume indicated on the cover page. ISSN: 2379-3252

NAFE C339/C396

PROPELLER CONTACT INJURY

PAGE 15

Table A-1

\begin{tabular}{rc} 
& Thrust v. RPM \\
\cline { 2 - 2 } RPM & Thrust (lb) \\
600 & 450 \\
800 & 700 \\
1000 & 950
\end{tabular}

Static steering force was measured by restraining the vessel at the bow and measuring tension in restraining cables at right angles to the vessel's centerline.

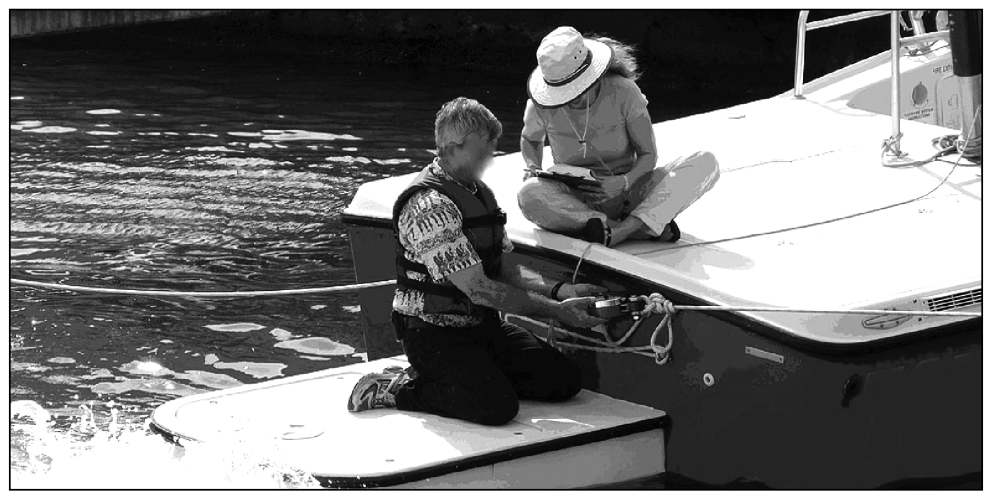

Figure A-3

Recording steering thrust

Table A-2

\begin{tabular}{ccc} 
& \multicolumn{2}{c}{ Steering Thrust } \\
\multicolumn{2}{c}{ Thrust } & Thrust \\
Rudder to Port & Rudder to STBD \\
RPM & $(\mathrm{lb})$ & (lb) \\
600 & 140 & 120 \\
800 & 220 & 210 \\
1000 & 350 & 320
\end{tabular}

These zero-speed static tests are valid quantifications in this case because the reported vessel speed at the time of the accident was very low. Thrust and steering force were initially balanced against aerodynamic force from the deployed parachute. 


\section{Propeller RPM decrement}

Propeller RPM decrement tests were conducted in wind and parachute loading conditions that approximated as closely as possible to those present at the time of the accident.

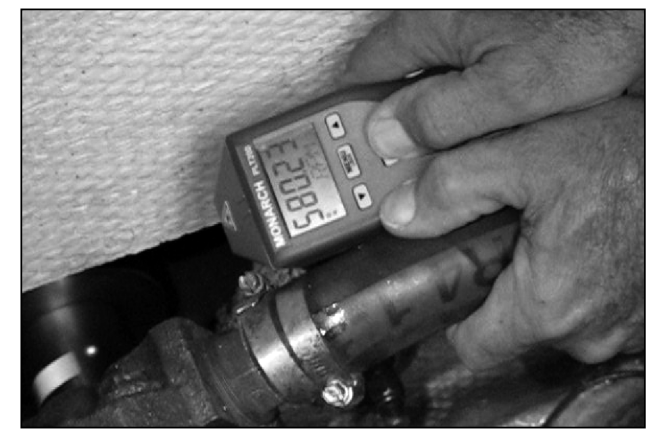

Figure A-4

RPM measuring device

Table A-3

\section{RPM Decrement Test Results}

$\begin{array}{ll}\text { Trial 1: } & 6.19 \text { seconds } \\ \text { Trial 2: } & 6.13 \text { seconds } \\ \text { Trial 3: } & 6.15 \text { seconds }\end{array}$

The handheld laser RPM meter, aimed at a marker on the propeller shaft produced a time history of the propeller RPM before and after the gearbox was shifted to neutral.

\section{Static roll stability}

Static roll stability was determined by means of an inclining test. These tests normally require a detailed description of the vessel's hull form in order to assess center of gravity and other mass properties for the purpose of determining compliance with regulatory requirements. However, for this application it was succinctly necessary to establish the relationship between heeling torque and heel angle, so both mass properties and hull form characteristics would drop from the calculation. The test was performed by moving a known weight, measured with acceptable precision by means of a domestic scale, across a known distance from one side of the vessel to the other. Total weight on board was approximately the same weight as at the time of the accident, and heel angle in response to the weight movement was measured photometrically (See Figure A-5). 
Copyright ( ) National Academy of Forensic Engineers (NAFE) http://www.nafe.org. Redistribution or resale is illegal.

Originally published in the Journal of the NAFE volume indicated on the cover page. ISSN: 2379-3252

NAFE C339/C396

PROPELLER CONTACT INJURY

PAGE 17

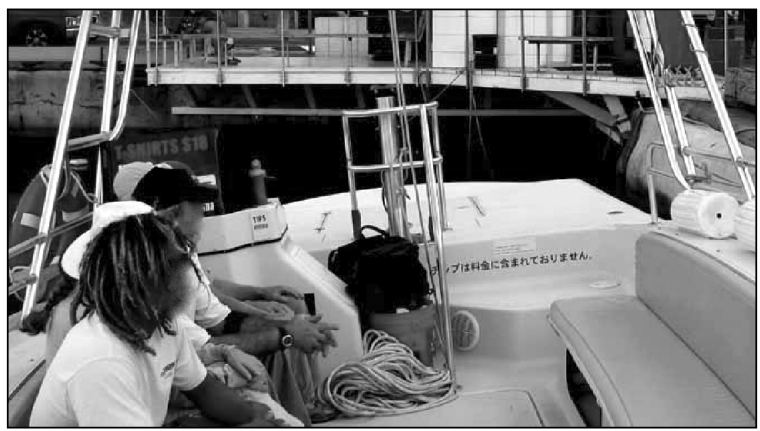

Figure A-5

Inclining test

Table A-4

\section{Results of Inclining Test}

Total weight moved $=836 \mathrm{lb}$.

Distance moved $=66 " "=5.5 \mathrm{ft}$.

Angle change, measured photometrically $=9.3$ degrees.

\section{Parachute towline force}

The parachute used for parasailing is circular with vents. In operation, it is towed horizontally but assumes an angle to the direction of motion, producing drag and lift (See Figures A-6 and A-7).

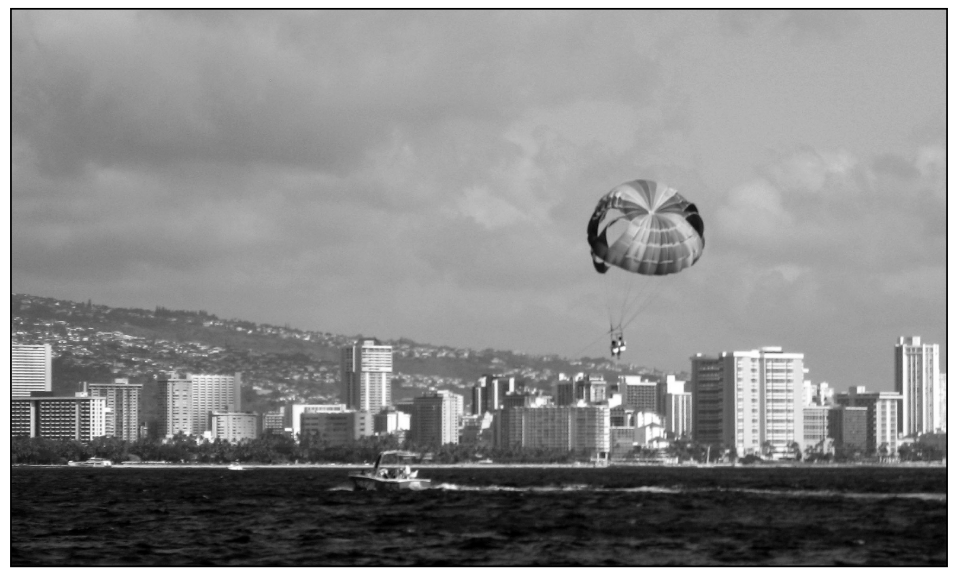

Figure A-6

Overall view of parasailing operation 
Data for for a "gliding" circular parachute is found in Fluid-Dynamic Drag, by Hoerner ${ }^{1}$ (see figure A-8).

By rotating the coordinate system of the gliding parachute 45 degrees, a reasonable approximation to the configuration of a parasail parachute under tow could be obtained. The lift and drag coefficients from Hoerner resolve to a towline force

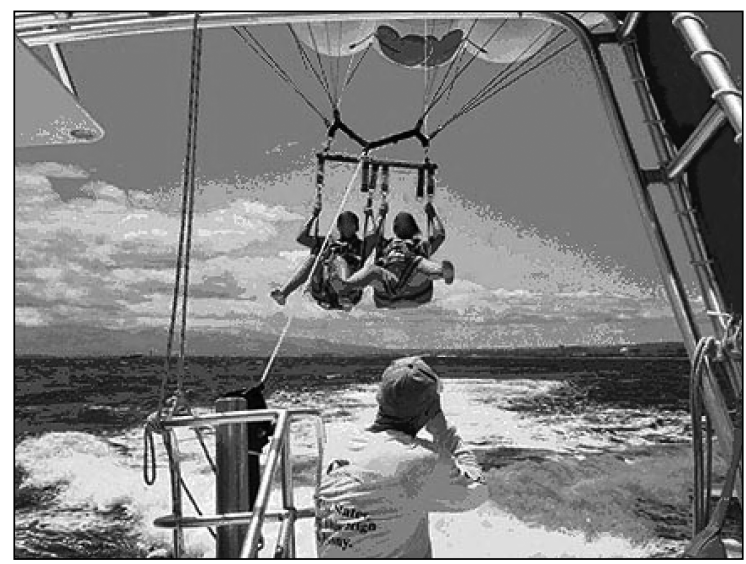

Figure A-7

Parasail towing geometry coefficient of 1.65, based on actual projected area of the inflated parachute. (Parachute diameter is customarily taken as the distance from edge to edge measured along the arc of the canopy, so drag coefficient based on nominal diameter would be considerably lower). See Table A-5 for results.

Table A-5

\section{Wind Speed v. Towline Force}

Wind Speed (knots)

15

20

25

30

35
Towline Force at 45 degree glide angle

$35 \mathrm{ft}$ diameter parachute (lb)

561

998

1559

2245

3056

\section{Steering sensitivity}

A simple test of the steering mechanism determined that the steering system was configured for 9.9 turns lock-to-lock. 


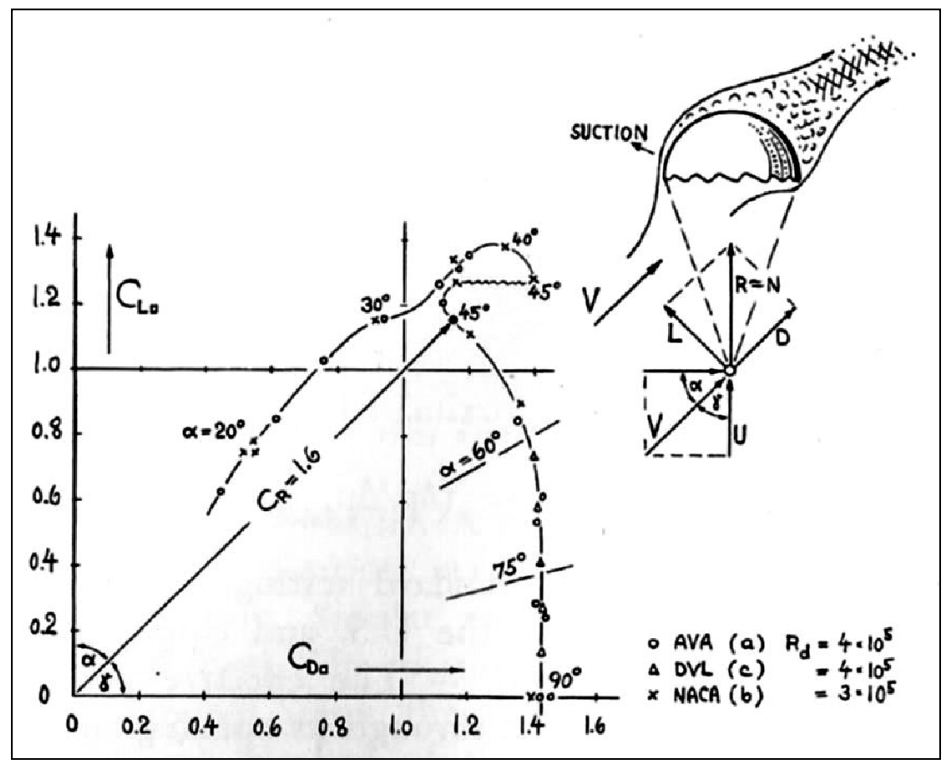

Figure A-8

Diagram of gliding parachute forces: aerodynamic characteristics of hemispherical shells, rigidly suspended in wind tunnels ${ }^{2}$

\section{Transverse drift test}

The drift speed and direction over the bottom while under transverse parachute load were measured by WAAS-enabled GPS (Garmin Map-76). The surface current vector was determined by measuring the speed and direction of a still-in-the-water drift, also by WAAS-enabled GPS, and subtracted out. The calculated resultant steady transverse speed through the water was 2.4 knots or 4.05 $\mathrm{ft} / \mathrm{sec}$ in 20 knot wind with a $29 \mathrm{ft}$ nominal diameter parachute deployed.

The estimated transverse force applied to the boat by the $29 \mathrm{ft}$ parachute in 20 knot wind equals $685 \mathrm{lb}$., resulting in a dimensional drag coefficient for the boat for transverse motion of $27.7\left(\mathrm{lb} /(\mathrm{ft} / \mathrm{sec})^{\wedge} 2\right)$

The added mass coefficient due to entrained water around the hull is approximated by standard methods. ${ }^{3}$

\section{Rotational inertia of propeller}

The rotational inertia of the propeller and entrained water (normally used for driveline vibration analysis but in this case useful for estimating the energy available to cause injury) are calculated using a spreadsheet developed by Chris Barry of the United States Coast Guard Small Craft Engineering Center. ${ }^{2}$ 
Copyright @ National Academy of Forensic Engineers (NAFE) http://www.nafe.org. Redistribution or resale is illegal.

Originally published in the Journal of the NAFE volume indicated on the cover page. ISSN: 2379-3252

PAGE 20

JUNE 2008 